\title{
Let-7a Inhibits T-Cell Proliferation and IFN- $\gamma$ Secretion by Down-Regulating STAT3 Expression in Patients with Psoriasis
}

\author{
Xiao-Ping Hua Qian Xie $^{b}$ Chao-Feng Chen ${ }^{a}$ Wei Zhang ${ }^{a}$ Bo Yu \\ aDepartment of Dermatology, Peking University Shenzhen Hospital, Shenzhen, bDepartment of \\ endocrinology, Peking University Shenzhen Hospital, Shenzhen, P.R. China
}

Key Words

Psoriasis $\bullet$ Let-7a $\cdot$ STAT3 $・$ Interferon- $\gamma \cdot$ T-cell $・$ Proliferation

\begin{abstract}
Objective: This study aimed to explore the effects of STAT3 targeting by let-7a on T-cell proliferation and IFN- $\gamma$ secretion in psoriasis. Methods: From January 2013 to January 2015, 40 patients with psoriasis (psoriasis group) and 38 volunteers undergoing plastic surgery (control group) were enrolled in this study. Pearson correlation analysis was performed to evaluate the correlation between let-7a and STAT3 expression. T-cells were isolated and subjected to different transfection methods. A dual luciferase reporter assay was carried out to confirm STAT3 as a target gene of let-7a. Let-7a, STAT3 and IFN- $\gamma$ mRNA expression was detected by quantitative real-time fluorescent polymerase chain reaction (qRT-PCR), and pSTAT3 protein levels were determined by Western blot. T-cell proliferation was evaluated with a cell counting kit-8 (CCK-8) assay. Results: The level of STAT3 mRNA and pSTAT3 was higher, but let-7a expression was lower in the psoriasis group than the control group. Pearson correlation analysis indicated that STAT3 expression was negatively correlated with let-7a expression. T-cells transfected with inhibitors exhibited greater IFN- $\gamma$ mRNA expression and T-cell proliferation than transfected T-cells and T-cells transfected with a non-sense sequence, while T-cells transfected with let-7a mimics exhibited lower IFN- $\gamma$ mRNA expression and T-cell proliferation than transfected T-cells and T-cells transfected with a non-sense sequence. This suggested that siRNA-STAT3 could reverse the increase in IFN-y mRNA expression and T-cell proliferation induced by let-7a inhibitors. Conclusion: Our results demonstrated that let-7a inhibits T-cell proliferation and IFN- $\gamma$ secretion by down-regulating STAT3 in psoriasis.
\end{abstract}

(C) 2017 The Author(s)

Published by S. Karger AG, Basel

\section{Introduction}

Psoriasis is a common, recurrent and chronic inflammatory skin disease that is often characterized by the development of erythematous papules and overlying scaly plaques $[1,2]$. As psoriasis progresses, patient symptoms become severe, and several systemic pathologies may consequently occur [3]. The prevalence of psoriasis ranges from $0 \%$ to $11.8 \%$ globally, and this disease commonly occurs in adults [4]. For instance, the prevalence of psoriasis in 
the US is approximately $2.2 \%$ to $3.2 \%$, and this translates to approximately 5 million psoriasis cases in adults [5]. Psoriasis is classified as a hyperproliferative and chronic inflammatory disease with unknown pathogenesis that may include immune system alterations, systemic or local factors, psychological stress, focal infections and the activation of leucocytes [6]. While psoriasis is considered an intrinsic epidermal keratinocyte disease with poor prognosis [7], previous studies have reported that knockdown of Wnt5a could inhibit the proliferation of keratinocytes [8] and Glycyrrhizin can be used as an anti-psoriasis drug [9]. It was recently linked to T-cells because it is a systemic inflammatory disease associated with the immune system [10]. Adaptive immune responses such as T-cell activation play important roles in the pathogenesis of psoriasis, and patients with psoriasis have been successfully managed using immunosuppressive drugs to inhibit both T-cell proliferation and cytokine production $[11,12]$. An increased number of IFN- $\gamma$-producing T-cells and activation of IFN- $\gamma$-induced immune response genes in psoriatic plaques enhance the pro-inflammatory phenotype of T-cells and contribute to keratinocyte hyperproliferation [13]. Although the number of treatments for patients with different psoriasis severity has rapidly increased, most of them fail to achieve skin clearance, and many patients are uncomfortable during these treatments [14].

Recently, attention has been paid to microRNAs (miRNAs), since they are involved in various human diseases, including cancers, immunological disorders and metabolic disorders [14]. Let-7 is a type of miRNA shows high sequence and functional conservation; there are ten mature let-7 isoforms with the same seed sequence [15]. Let-7a mainly regulates anti-inflammatory effects by repressing specific genes and targeting downstream signaling pathways. The inappropriate regulation of anti-inflammatory effects by let-7a may lead to a less-differentiated cellular state and trigger the development of cell-based diseases [16]. Moreover, assessment of the STAT3 transcript as a miRNA target showed that let-7a is an important suppressor of STAT3 [17]. A substantial increase in the level of STAT3 has been linked to many epithelial cell malignancies, since it has several effects on cellular physiology through the transcriptional switching of several gene promoters [18]. STAT3 activation is associated with several cytokines and growth factors that are up-regulated in patients with psoriasis $[19,20]$. Moreover, Cesare et al. revealed that STAT3 was associated with psoriasis through the IL-23 signaling pathway [21]. Recently, the relationship between miRNA and psoriasis has stimulated great interest $[22,23]$, However, according to TargetScan (http:// www.targetscan.org/vert_71/), few studies have investigated the target relationship between miRNAs and STAT3, and we still do not know which specific miRNAs target STAT3 in psoriasis.

In this study, we investigated the effects of let-7a on IFN- $\gamma$ secretion and T-cell proliferation in patients with psoriasis. Furthermore, we aimed to explore the underlying mechanism by predicting the target genes of let-7a.

\section{Materials and Methods}

\section{Study subjects}

From January 2013 to January 2015, 40 patients with psoriasis (psoriasis group) in Peking University Shenzhen Hospital were enrolled in this study, including 22 males and 18 females with an age range of 23-56 years, a mean age of $36 \pm 7$ years, and a disease duration from 50 days to 27 years. In line with the diagnostic criteria for psoriasis vulgaris [24], all the enrolled patients had the following typical clinical manifestations: continuously raised and diffuse red rashes, relatively thin scales and obvious inflammation with significant itchiness surrounded by pink skin. All patients were confirmed by pathology to have psoriasis vulgaris. The inclusion criteria were as follows: patients did not receive systemic or local treatment with psoriasis drugs (including corticosteroids, immuno-suppressants and psoralen ultraviolet-A (PUVA) therapy) two months before enrollment; patients stopped using local glucocorticoids and other drugs for topical use for at least four weeks; patients had no systemic application of anti-psoriasis drugs, including oral corticosteroids, immunosuppressive agents, etc., for more than six weeks; and patients did not have accompanying heart,

\section{KARGER}




\section{Cellular Physiology Cell Physiol Biochem 2017;42:115-125 \begin{tabular}{l|l|l} 
and Biochemistry $10.1159 / 000477120$ & $\begin{array}{l}\text { DO } 2017 \text { The Author(s). Published by S. Karger AG, Basel } \\
\text { www.karger.com/cpb }\end{array}$
\end{tabular}}

Hu et al.: Effects of STAT3 Targeting by Let-7a on T-Cells in Psoriasis

liver or kidney dysfunction or other systemic disorders. The severity of the disease in patients with psoriasis was determined in accordance with the psoriasis area and severity index (PASI), and the PASI scores of patients with psoriasis were recorded [25] The PASI scores of the patients with psoriasis were 8.3-46.9 (averaged 28.5).

A total of 38 volunteers undergoing plastic surgery (normal group) in Peking University Shenzhen Hospital were enrolled as the control group, which excluded patients with psoriasis and other skin disease and consisted of 16 males and 22 females with an age range of 26-55 years and a mean age of $34 \pm 6$ years. No significant differences were found in age, sex or course of disease between the psoriasis group and the normal group (all $P>0.05$ ). All patients signed informed consents. The present study was approved by the Ethics Committee of Peking University Shenzhen Hospital [26].

\section{Isolation of peripheral blood T-cells}

Density gradient centrifugation of stratified fluid was used to separate peripheral blood mononuclear cells from the psoriasis group and the control group. Skin lesions from patients with psoriasis and normal skin samples from patients undergoing plastic surgery were obtained, placed into cryogenic tubes, and stored in liquid nitrogen. A blood sample ( $8 \mathrm{~mL}$ ) was drawn from each subject for anti-coagulation with ethylenediaminetetraacetic acid (EDTA) in vitro and stored in sterile tubes. Anti-coagulated blood was diluted with an equal amount of phosphate-buffered saline (PBS) and was carefully layered on the FicollUrografin stratified fluid (specific gravity 1.077), which was then centrifuged with a horizontal centrifuge (2500 rpm, $20 \mathrm{~min}$ ). Mononuclear cells were suspended in the upper layer of the stratified liquid and appeared as a white film. The mononuclear cell layer was removed with a capillary pipette, washed with PBS and centrifuged three times (1500 rpm, $7 \mathrm{~min}$ ). Peripheral blood T-cells were separated with a magnetic cell separator (MACS) (Dynabeads CD3, Dynal Biotech Company, Oslo, Norway) in accordance with the instructions, prepared as a cell suspension in Roswell Park Memorial Institute (RPMI)-1640 medium containing $10 \%$ fetal calf serum, and stimulated with $5 \mu \mathrm{g} / \mathrm{mL}$ phytohemagglutinin (PHA) in vitro.

\section{Dual luciferase reporter assay}

The let-7a binding sites in the 3' untranslated region (UTR) of STAT3 were predicted with TargetScan (httn://www.targetscan.org/). Using the principles of primer design and the 3'UTR sequence of the STAT3 gene in GenBank as a sequence model, primers that added two restriction enzyme sites (EcoRI and NotI) were designed with Primer Premier 5.0 software (Premier Biosoft International, Palo Alto, CA): STAT33'UTR F: 5'-CCG GAA TTC GGA GCT GAA ACC AGA AGC-3', STAT3-3'UTR R: 5'-ATT TGC GGC CGC AGG GTC TGG AGT CTG GGT-3', STAT3-3'UTR-MUT F: 5'-CCG GAA TTC GGG CAG TTT TTA AAA TAG-3', STAT3 3'UTRMUT R: 5'-AAA TAT GCG GCC GCG AAA CTG CAG AGC-3'. The STAT3 3'UTR and STAT3 3'UTR-MUT sequences were amplified by PCR. The products amplified with STAT3-3'UTR and STAT3 3'UTR-MUT were linearized with restriction enzymes. Then, the enzyme-digested products were incubated at $37^{\circ} \mathrm{C}$ overnight and subjected to $1 \%$ agarose electrophoresis for gel extraction guided by an ultraviolet imager. Subsequently, the gene fragment and linear expression vector were subjected to centrifugation at 12,000 rpm for $5 \mathrm{~s}$ and transformed into E. coli $\mathrm{DH} 5 \alpha$ at $16^{\circ} \mathrm{C}$ overnight. After the dual luciferase reporter gene plasmid was obtained, peripheral blood T-cells were transfected for $24 \mathrm{~h}$ by liposome-mediated gene transfection. Ultimately, the fluorescence intensity was evaluated using the Dual-Luciferase ${ }^{\circ}$ Reporter Assay System (Promega Corp., Madison, Wisconsin, USA) according to the kit instructions.

\section{Cell transfection and grouping}

Isolated peripheral blood T-cells were divided into six groups: a blank group, a negative control (NC) group (transfected with a non-sense sequence; non-seq group), a let-7a inhibitor group (transfected with the let-7a inhibitor sequence), a let-7a mimics group (transfected with the let-7a mimics sequence), an siRNASTAT3 group and an siRNA-STAT3 + let-7a inhibitor group. The preparation of the let-7a inhibitor and mimics (GenePharma Co, Ltd., Shanghai, China) was as follows: let-7a inhibitor: 5'-AACUAUACAACCUACUACCUCA-3; let-7a mimics: 5'-UGAGGUAGUAGGUUGUAUAGUU-3' and 5'-CUAUACAACCUACUACCUCAUU-3'; and let-7a non-sense sequence: 5'-CAGUACUUUUGUGUAGUA-3'. Peripheral blood T-cells $\left(1 \times 10^{6} / \mathrm{ml}\right)$ were placed in 6-well plates and cultured at $37^{\circ} \mathrm{C}$ in $5 \% \mathrm{CO}_{2}$ for $24 \mathrm{~h}$. As described in the instructions (Invitrogen, Inc., Carlsbad, California, USA), the diluted let-7a inhibitor, let-7a mimics, let-7a non-sense sequences and diluted Lipofectamine-2000 were mixed with an equal amount of the corresponding nucleotides evenly and gently. 


\section{Cellular Physiology Cell Physiol Biochem 2017;42:115-125

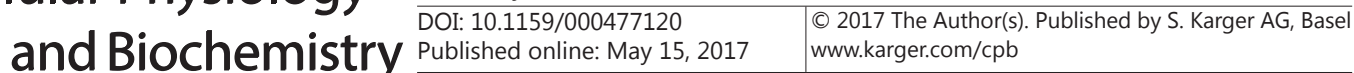

Hu et al.: Effects of STAT3 Targeting by Let-7a on T-Cells in Psoriasis

Then, the mixture was incubated at room temperature for 20 min to allow the formation of complexes of inhibitors, mimics, and non-sense sequences with their corresponding nucleotide/Lipofectamine-2000. After the prepared cells in the plates were washed twice with PBS, $2 \mathrm{~mL}$ fresh serum-free MEM and $500 \mu \mathrm{L}$ of the RNA/Lipofectamine-2000 complexes were added to each well of the 6-well plates and mixed well. The 6-well plates were placed in a $\mathrm{CO}_{2}$ incubator at $37^{\circ} \mathrm{C}$.

\section{Quantitative real-time fluorescent polymerase chain reaction ( $q R T-P C R$ )}

The expression of let-7a, STAT3 and IFN- $\gamma$ in serum and cells was detected after transfection. Total RNA was extracted according to the kit instructions (Promega Corp., Madison, Wisconsin, USA). The optical density (OD) 260/280 values of the RNA samples were measured using an ultraviolet spectrophotometer to calculate RNA concentration, and the RNA samples were stored at $-80^{\circ} \mathrm{C}$ until further use. Primers were designed with the primer design software Primer 5.0 (Premier Biosoft International, Palo Alto, Canada) (Table 1) using the gene sequences published in the GenBank database. A reverse transcription PCR amplification reaction was performed to synthesize cDNA, and an ABI 7500 Real-time PCR System (Applied Biosystems, Inc., Foster City, California, USA) was used for qRT-PCR.

The PCR amplification conditions for let-7a were as follows: a $10 \mu \mathrm{L}$ reaction volume $(5 \mu \mathrm{L} 2 \times$ SYBR Green Taq reaction solution, $0.2 \mu \mathrm{L}$ RoxII, $0.2 \mu \mathrm{L}$ of each sense and antisense primer (10 $\mu \mathrm{mol} / \mathrm{L})$, and $1 \mu \mathrm{L}$ cDNA) was subjected to 40 cycles of $95^{\circ} \mathrm{C}$ for $30 \mathrm{~s}, 95^{\circ} \mathrm{C}$ for $5 \mathrm{~s}$, and $60^{\circ} \mathrm{C}$ for $30 \mathrm{~s}$. U6 was used as an internal control.

The PCR reaction for STAT3 contained $10 \mu \mathrm{L} 2 \times$ Super Real Premix Plus, $0.6 \mu \mathrm{L}$ of each upstream and downstream primer, $4 \mu \mathrm{L}$ reverse transcription products, $2 \mu \mathrm{L} 50 \times$ ROX, and $2.8 \mu \mathrm{L}$ RNase-free water. The reaction conditions included pre-denaturation at $95^{\circ} \mathrm{C}$ for $15 \mathrm{~min}$, then 40 cycles of denaturation at $95^{\circ} \mathrm{C}$ for $10 \mathrm{~s}$, annealing for $30 \mathrm{~s}$ and extension for $30 \mathrm{~s}$. The PCR reaction for $I F N-\gamma$ contained $10 \mu \mathrm{L} 5 \times$ quantitative PCR buffer, $1 \mu \mathrm{L}$ of each upstream and downstream primer, $0.5 \mu \mathrm{L}$ dNTPs, $1 \mu \mathrm{L}$ fluorescent probe (Sangon Biotech, Shanghai, China), $1.5 \mu \mathrm{L}$ Taq polymerase (Applied Biosystems, Inc., Foster City, California, USA), 5

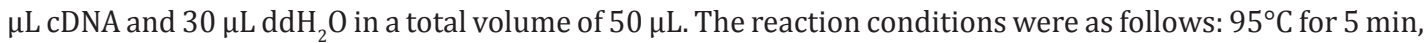
then 30 cycles of $94^{\circ} \mathrm{C}$ for $30 \mathrm{~s}, 53.2^{\circ} \mathrm{C}$ for $30 \mathrm{~s}$ and $72^{\circ} \mathrm{C}$ for $1 \mathrm{~min}$, and then further extension at $72^{\circ} \mathrm{C}$ for 7 min. $\beta$-Actin was used as an internal control. The PCR results were evaluated with melting curves. CT values (inflection point of amplified power curve) were obtained, and gene relative expression was calculated using the $2^{-\Delta \Delta \mathrm{Ct}}$ method.

\section{Western blotting}

Total protein was extracted from peripheral T-cells. Protein concentrations were measured as described in the instructions of the bicinchoninic acid (BCA) kit (Boster Company, Wuhan, China). Then, the extracted proteins were added to sample buffer, the mixture was boiled at $95^{\circ} \mathrm{C}$ for $10 \mathrm{~min}$, and $30 \mu \mathrm{g}$ of the mixture was added to each well. The proteins were separated by electrophoresis in $10 \%$ polyacrylamide gels (Boster Company, Wuhan, China) at an initial electrophoresis voltage of $80 \mathrm{~V}$ followed by a voltage of $120 \mathrm{~V}$, transferred to a polyvinylidene fluoride (PVDF) membrane at a membrane transfer voltage of 100 $\mathrm{mV}$ for 45-70 min, and blocked with 5\% bovine serum albumin (BSA) at room temperature for $1 \mathrm{~h}$. The

Table 1. Primer sequences for qRT-PCR. Note: qRT-PCR, quantitative real-time fluorescent polymerase chain reaction; RT, reverse transcription

\begin{tabular}{lll}
\hline Primer & & Primer sequence (5'-3') \\
\hline Let-7a stem-loop structure & RT primer & GTCGTATCCAGTGCAGGGCGAG \\
& PCR upstream primer & GTATTCGCACTGGATACGACAACTA \\
& miRNA universal downstream & GCGCTGAGGTAGTAGGTTGTA \\
primer & GTGAGGTCCGAGGT \\
U6 & Upstream primer & CTCGCTTCGGCAGCACA \\
& Downstream primer & AACGCTTCACGAATTTGCGT \\
STAT3 & Upstream primer & CAGAGCCCCATTTTCTGGTA \\
& Downstream primer & AGGACAGGGAGTGGTGTTTG \\
IFN- $\gamma$ & Upstream primer & TTCTTACAACACAAAATCAAATCA \\
& Downstream primer & TCAACAAAGCTGATACTCCA \\
$\beta$-actin & TaqMan Probe & CCAACGCAAAGCAATACATGAACT \\
& Upstream primer & GCCATCCTGCGTCTG \\
& Downstream primer & GGGGCATCGGAACCGCT \\
\hline
\end{tabular}




\section{Cellular Physiology Cell Physiol Biochem 2017;42:115-125

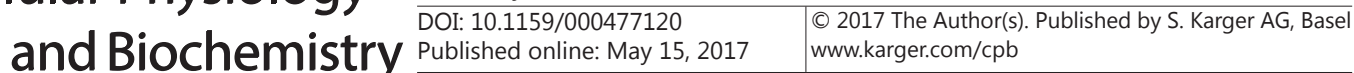

Hu et al.: Effects of STAT3 Targeting by Let-7a on T-Cells in Psoriasis

primary antibody against pSTAT3 (Cell Signaling Technology, Beverly, Massachusetts, USA; diluted 1:1000) was added, and the mixture was incubated at $4^{\circ} \mathrm{C}$ overnight before being rinsed with TBST 3 times for 5 min each time. The corresponding secondary antibody was added and incubated at room temperature for $1 \mathrm{~h}$, and the membrane was washed 3 times for $5 \mathrm{~min}$ each time. Chemiluminescent reagent was used to visualize the bands. $\beta$-Actin was used as an internal control. A Bio-Rad Gel Doc EZ imager (Bio-Rad, Hercules, California, USA) was used to develop the photos. The intensity of the bands of interest was analyzed with ImageJ software (Rawak Software, Inc. Munich, Germany), and the relative protein expression levels were expressed as the ratio of the intensity of the target protein band to the value of the internal control.

Cell counting kit-8 (CCK-8) assay

As described in the kit instructions (Dojindo Laboratories, Kumamoto, Japan), $100 \mu \mathrm{L}$ isolated peripheral T-cell suspension was prepared, added to 96 well-plates, and cultured for $0 \mathrm{~h}, 24 \mathrm{~h}, 48 \mathrm{~h}, 72 \mathrm{~h}$ or $96 \mathrm{~h}$. Then, $10 \mu \mathrm{L}$ of CCK-8 solution was added, and the mixture was incubated for 1-4 h. Then, the optical density (OD) was determined at $405 \mathrm{~nm}$. The proportion of T-cells proliferating was calculated $0 \mathrm{~h}, 24 \mathrm{~h}, 48$ h, $72 \mathrm{~h}$ and $96 \mathrm{~h}$ after transfection using a CCK-8 kit.

\section{Statistical analysis}

SPSS 18.0 statistical software (Stata Corp LP, College Station, Texas, USA) was used for data analysis. Measured data were expressed as the mean \pm standard deviation. Comparisons between two groups of measured data that were normally distributed were made with a t-test and paired $t$-test; count data were expressed as percentage or rate, and comparisons were made with a chi-square test. Correlations were analyzed with Pearson correlation test, and $P<0.05$ was considered statistically significant.

\section{Results}

Expression of let-7a and STAT3 in the psoriasis group and the normal group

The qRT-PCR results demonstrated that STAT3 mRNA expression was higher and let-7a expression was significantly decreased in the psoriasis group compared with the control group (both $P<0.05$ ) (Fig. 1A). Western blot analysis indicated that pSTAT3 protein expression was clearly higher in the psoriasis group than the normal group $(P<0.05)$ (Fig. 1B). Pearson's correlation test showed that STAT3 expression was negatively correlated with let-7a expression $(\mathrm{r}<0, P<0.05)$ (Fig. 1C).

The relationship between let-7a expression and clinicopathological features of patients with psoriasis

The expression of let-7a did not differ significantly with onset age, course of disease, number of plaque lesions or clinical stage of psoriasis (all $P>0.05$ ), but it did differ significantly among PASI scores $(P<0.05)$ (Table 2$)$.

\section{STAT3 is a target gene of let-7a}

The let-7a target genes were predicted using TargetScan (http: //www.targetscan. org/), which identified STAT3 as one of the let-7a target genes. The let-7a binding site in the STAT3 3'UTR is highly conserved in mammals (Fig. 2A). The dual luciferase reporter gene assay results showed that relative luciferase activity was significantly lower after co-transfection of the wild-type STAT3 3'UTR-WT and let-7a mimics $(\mathrm{P}<0.01)$, but there was no obvious difference in expression after co-transfection of the mutant STAT3 3'UTRMUT expression vector and let-7a mimics (Fig. 2B). These results were consistent with the bioinformatics prediction results, which further confirmed that let-7a can bind to the 3'UTR region of STAT3 mRNA, suggesting that STAT3 is a target gene of let-7a.

Expression of let-7a and STAT3 in each transfected group

Peripheral blood T-cells were obtained from patients with psoriasis for the let-7a transfection experiments, and the results showed that the expression of let-7a, pSTAT3 


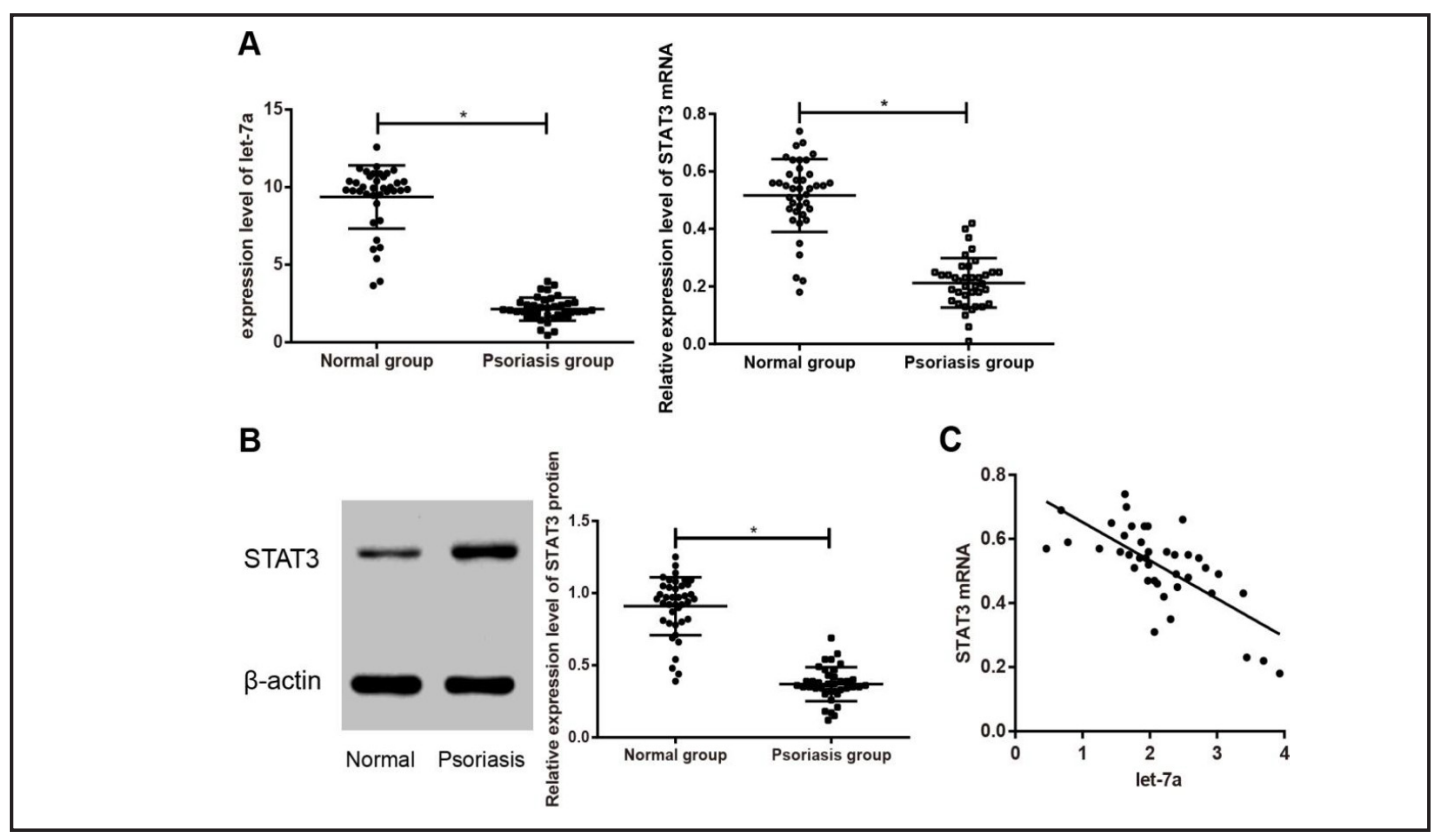

Fig. 1. Let-7a and STAT3 expression in patients with psoriasis $(n=40)$ and normal controls $(n=38)$ and Pearson correlation analysis for Let-7a and STAT3 expression. (A. The expression of let-7a and STAT3 mRNA in patients with psoriasis and normal controls was detected by qRT-PCR; B. STAT3 protein levels in patients with psoriasis and normal controls were detected by Western blotting; C. Pearson correlation scatter plot). Note: STAT3, signal transducer and activator of transcription 3; qRT-PCR, quantitative real-time fluorescent polymerase chain reaction; ${ }^{* *}$, compared with the normal group, $P<0.05$.

Table 2. Relationships between let-7a expression and clinicopathological features of psoriasis. Note: PASI, psoriasis area and severity index

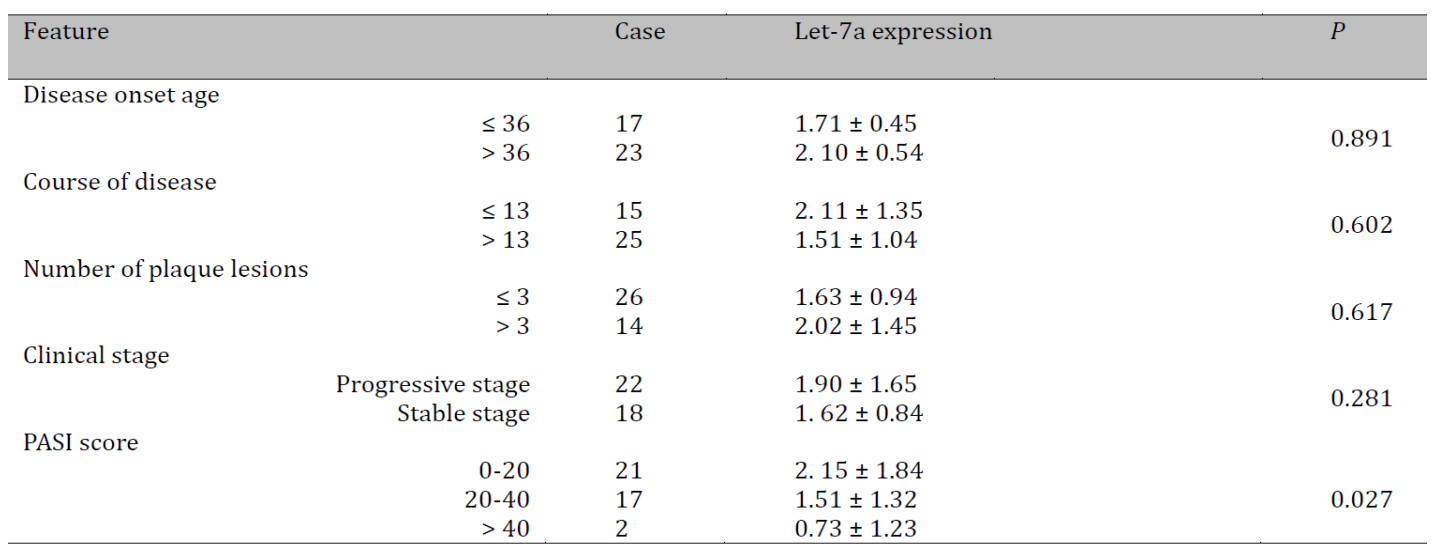

protein and STAT3 mRNA did not differ significantly between the blank group and the NC group (both $P>0.05$ ). Compared with the blank group and the NC group, let-7a expression was significantly lower, while the level of pSTAT3 protein and STAT3 mRNA was significantly higher in the let-7a inhibitor group (all $P<0.05$ ). Let-7a expression was significantly higher in the let-7a mimics group, while the level of pSTAT3 protein and STAT3 mRNA was significantly lower in this group (all $P<0.05$ ). The level of pSTAT3 protein and STAT3 mRNA was significantly lower in the siRNA-STAT3 group (all $P<0.05$ ). Compared with the let-7a inhibitor group, the level of pSTAT3 protein and STAT3 mRNA was significantly lower in the siRNA-STAT3+let-7a inhibitor group (both $P<0.05$ ), while the level of pSTAT3 protein and STAT3 mRNA was significantly lower in the siRNA-STAT3 group than the blank group and the NC group (Fig. 3). 
Fig. 2. Comparison of relative luciferase activity after co-transfection of the STAT3 3'UTR and let7 a mimics (A. Paired nucleotide sequence diagram of let-7a and STAT3 3'UTR; B. Relative luciferase activity after transfection of STAT3 3'UTR-WT or 3'UTR-MUT with let-7a mimics). Note: NC, negative control; STAT3, signal transducer and activator of transcription 3; UTR, untranslated region; WT, wild type; MUT, mutant; ${ }^{* *}$, compared with the negative control group (transfected with the non-sense sequence), $P<0.01$. This experiment was repeated 3 times, and the data were averaged.
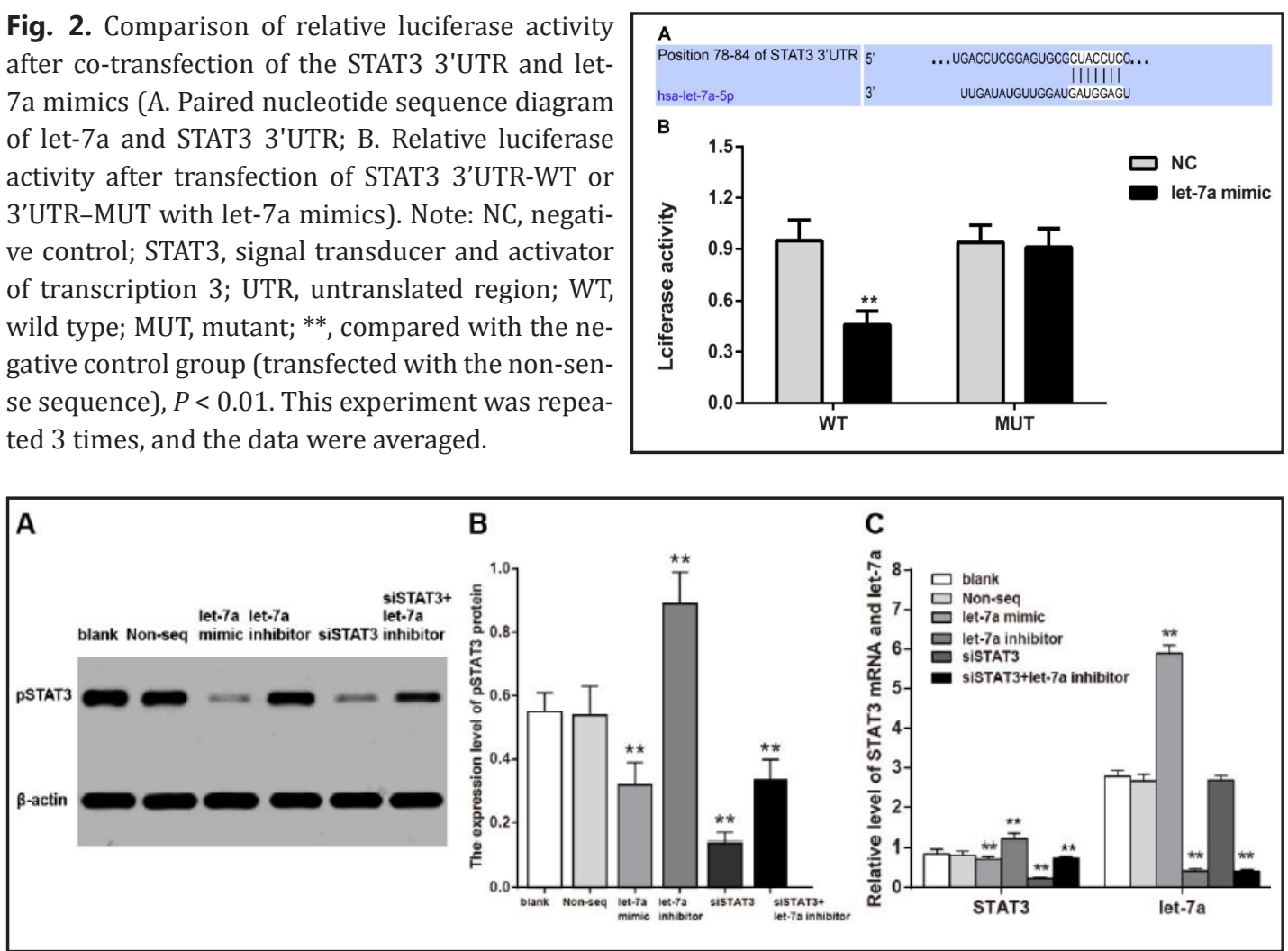

Fig. 3. Let-7a and STAT3 expression after T cells transfection with let-7a (A. The level of pSTAT3 in each group was detected by Western blotting; B. The level of pSTAT3 protein in each group after transfection with let-7a; C. The expression of let-7a and STAT3 mRNA after transfection was detected by qRT-PCR). Note: STAT3, signal transducer and activator of transcription 3; qRT-PCR, quantitative real-time fluorescent polymerase chain reaction; Non-seq, non-sense sequence; ${ }^{* *}$, compared with the blank group and the negative control group, $P<0.01$. This experiment was repeated 3 times, and the data were averaged.

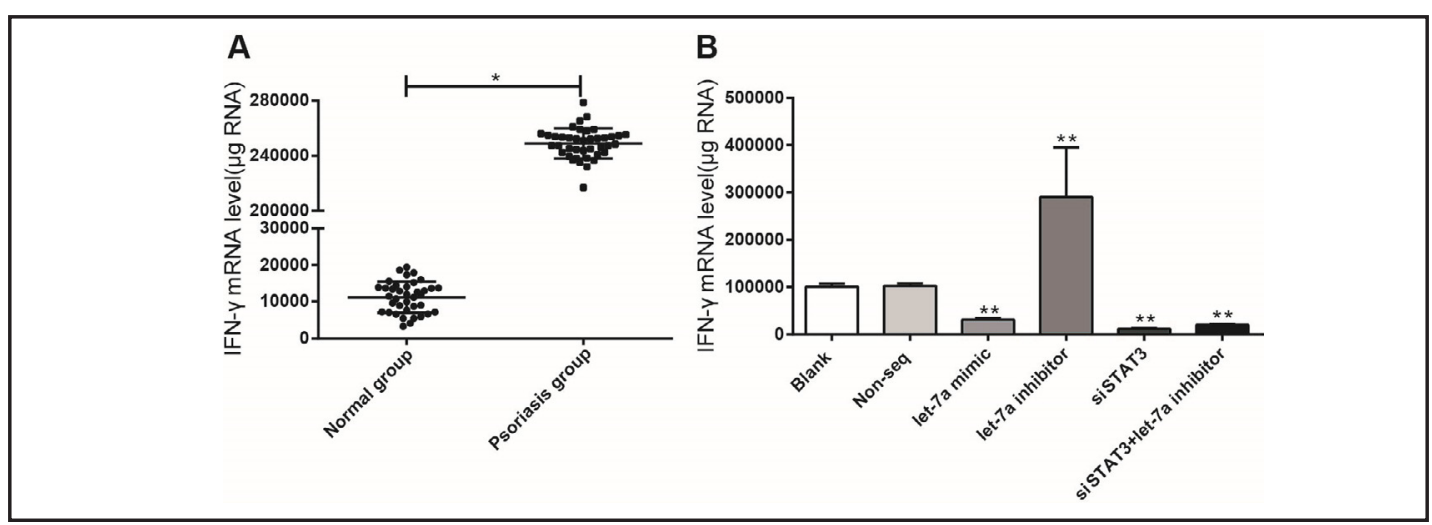

Fig. 4. Comparison of IFN- $\gamma$ mRNA expression in each group (A. The IFN- $\gamma$ mRNA expression in the patients with psoriasis and the normal controls. B. Comparison of IFN- $\gamma$ mRNA expression after peripheral blood T cells from each group were transfected with the let-7a inhibitor or mimics). Note: Non-seq, non-sense sequence; ${ }^{* *}$, compared with the blank group and the negative control group, $P<0.01$.

\section{Effects of let-7a on IFN- $\gamma$ secretion by T-cells from patients with psoriasis}

The qRT-PCR detection result showed that IFN- $\gamma$ mRNA expression was clearly higher in the psoriasis group than the normal group $(P<0.05)$ (Fig. 4A). After transfection of peripheral blood T-cells from patients with psoriasis, no significant difference in the expression of IFN- $\gamma$ 

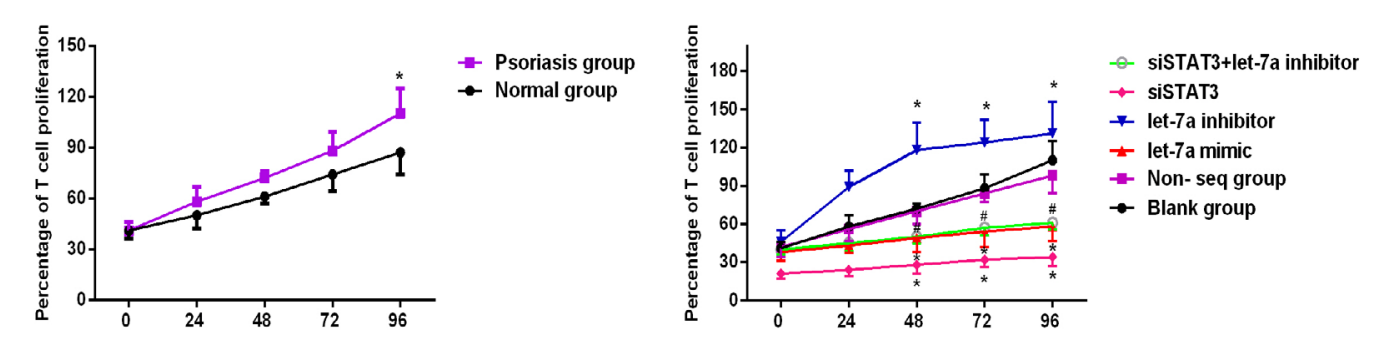

Fig. 5. Effects of let-7a on T cell proliferation in each group (A. The percentage of T cells proliferating in peripheral blood for the patients with psoriasis and the normal controls at each time point; B. The percentage of $\mathrm{T}$ cells proliferating in peripheral blood for the patients with psoriasis at each time point after transfection). Note: Non-seq, non-sense sequence; ", compared with the blank group and the negative control group, $P<$ 0.05 ; , compared with the let-7a inhibitor group, $P<0.05$. This experiment was repeated 3 times, and the data were averaged.

mRNA was observed between the blank group and the NC group $(P>0.05)$. Compared with the blank group and the NC group, IFN- $\gamma$ mRNA expression was significantly higher in the let7 a inhibitor group, while it was significantly lower in the let-7a mimics group and the siRNASTAT3 group (all $P<0.05$ ). However, it was significantly lower in the siRNA-STAT3+let-7a inhibitor group than the let-7a inhibitor group (all $P<0.05$ ), suggesting that siRNA-STAT3 could reverse the increase in IFN- $\gamma$ mRNA expression induced by let-7a inhibitors (Fig. 4B).

\section{Effects of let-7a on T-cell proliferation in each group}

After separation of peripheral blood T-cells, a CCK-8 assay was used to determine the proportion of cells proliferating at $0 \mathrm{~h}, 24 \mathrm{~h}, 48 \mathrm{~h}, 72 \mathrm{~h}$ and $96 \mathrm{~h}$. The results showed that the the proportion of T-cells proliferating in the psoriasis group was clearly higher than that in the normal group at $96 \mathrm{~h}(P<0.05)$ (Fig. 5A). The results showed that the proportion of T-cells proliferating was clearly higher in the let-7a inhibitor group than the blank group and the NC group at $48 \mathrm{~h}, 72 \mathrm{~h}$, and $96 \mathrm{~h}$ after transfection (all $P<0.05$ ), while it was significantly lower in the let-7a mimics group and the siRNA-STAT3 group at $48 \mathrm{~h}, 72 \mathrm{~h}$ and $96 \mathrm{~h}$ (all $P<$ 0.05). The the proportion of T-cells proliferating in the siRNA-STAT3+let-7a inhibitor group was significantly lower than that in the let-7a inhibitor group at $48 \mathrm{~h}, 72 \mathrm{~h}$ and $96 \mathrm{~h}$ (all $P<$ 0.05), suggesting that siRNA-STAT3 could reverse the increase in the proportion of T-cells proliferating induced by let-7a inhibitors (Fig. 5B).

\section{Discussion}

In this study, we found that let-7a inhibits STAT3 expression, thereby inhibiting T-cell proliferation and IFN- $\gamma$ secretion in psoriasis. The luciferase assay results showed the existence of a targeting relationship between let-7a and STAT3. Moreover, Pearson correlation analysis also showed a negative correlation between STAT3 and let-7a levels. Ectopically expressed let-7a can induce cellular transformation by activating STAT3, and knockdown of STAT3 inhibits let-7a-induced transformation, while restoring STAT3 relieves this inhibition [27]. Let-7a might contribute to the constitutively increased phosphorylation of STAT-3 by involving the neurofibromatosis 2 gene [28]. In addition, let-7a and miR-21 might interact with the STAT3 signaling pathway and affect the development of cervical cancer [18].

One of our results showed that, compared with the normal group, let-7a expression was significantly lower in the psoriasis group and was associated with PASI scores, while the levels of STAT3 mRNA and pSTAT3 protein were clearly higher in the psoriasis group. Dysregulation of serum let-7d levels was found in patients with psoriasis compared with normal subjects, 


\section{Cellular Physiology Cell Physiol Biochem 2017;42:115-125

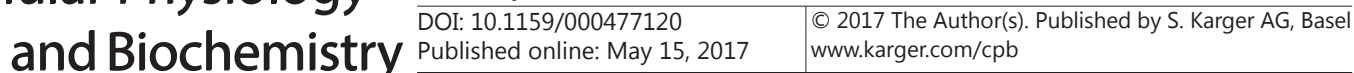

Hu et al.: Effects of STAT3 Targeting by Let-7a on T-Cells in Psoriasis

and let-7a supplementation improved skin fibrosis induced by bleomycin [29]. In addition, down-regulation of let-7a contributes to excessive type I collagen expression in systemic and localized scleroderma, which is also a skin disease [30]. Up-regulation of STAT3 expression is linked with a psoriatic phenotype in over $90 \%$ of patients with psoriasis, and patients overexpressing STAT3 in the epidermis developed psoriatic plaques in response to mild injury, while inhibition of STAT3 prevents the development of such lesions [31]. STAT3 is necessary for regulating pro-inflammatory cytokine signaling, which is involved in several functions of Th17 cells, which seem to be involved in the majority of auto-immune diseases, including psoriatic arthritis [32]. STAT3 is activated by increased levels of cytokines in the epidermal keratinocytes of psoriatic lesions, and targeting STAT3 may lead to a treatment for psoriasis [33].

Another important result showed that IFN- $\gamma$ mRNA expression levels were clearly higher in the psoriasis group than the normal group. Compared with the blank group and the NC group, IFN- $\gamma$ mRNA expression was significantly higher in the let-7a inhibitor group and significantly lower in the let-7a mimics group, which might be due to the inhibition of STAT3 expression by let-7a. Our study results also revealed that the proportion of T-cells proliferating and IFN- $\gamma$ mRNA expression were significantly lower in the siRNA-STAT3 group, but they were significantly lower in the siRNA-STAT3+let-7a inhibitor group than in the let-7a inhibitor group, suggesting that siRNA-STAT3 could reverse the increase in the proportion of T-cells proliferating and IFN- $\gamma$ mRNA expression that were induced by let-7a inhibitors. IFN- $\gamma$ has been postulated to be a key cytokine in the development of psoriasis, as IFN- $\gamma$ mRNA is elevated in skin lesions, IFN- $\gamma$ is increased in the serum of patients with psoriasis, and increased expression of IFN- $\gamma$-regulated genes was found in lesions [34]. In addition, CD8 + T-cells can orchestrate skin inflammation with psoriasis-like pathology in keratinocytes primarily by mediating IFN- $\gamma$ expression [34]. STAT3 plays an important role in the IFN signaling pathway, which is strongly related to most autoimmune processes [35]. In addition, STAT3 activation was found to mediate IFN- $\gamma$-induced neurotoxicity and intercellular adhesion molecule-1 expression in human astrocytes [36].

Furthermore, the proportion of T-cells proliferating at $96 \mathrm{~h}$ was clearly higher in the psoriasis group than in the normal group. The proportion of T-cells proliferating was clearly higher in the let-7a inhibitor group, while it was significantly lower in the let-7a mimics group, which might be due to the targeting of STAT3 by let-7a. A marked increase in the number of proliferating memory-type T-cells has been observed in lesional psoriasis due to the continuous activation of lesional antigen-presenting cells [37]. Moreover, psoriasis is a T-cell driven chronic inflammatory skin disease, and both T helper (Th) 1 and Th17 cells participate in psoriasis pathogenesis [38]. STATs play critical roles in cell growth and survival by inhibiting apoptosis and the differentiation of many cells and are particularly important in auto-immune processes, as they control T-cell differentiation [39]. A high level of STAT3 phosphorylation is associated with pSTAT1 and pErk, which cause the release of T-cell proliferation suppression [40]. STAT3 signaling is involved in specific T helper cell differentiation and human central memory T-cell formation to control certain chronic viruses [41].

Taken together, these results indicate that let-7 can regulate T-cell proliferation and IFN- $\gamma$ secretion in psoriasis by targeting STAT3 and suppressing its expression. Furthermore, siRNA-STAT3 reversed the increase in the proportion of T-cells proliferating and IFN- $\gamma$ mRNA expression induced by let-7a inhibitors, thus indicating that up-regulation of let-7a can inhibit the expression of STAT3 to affect the development of psoriasis.

\section{Acknowledgments}

We would like to give our sincere appreciation to the reviewers for their helpful comments about this manuscript. 


\section{Cellular Physiology Cell Physiol Biochem 2017;42:115-125 \begin{tabular}{l|l|l} 
DOI: 10.1159/000477120 & O 2017 The Author(s). Published by S. Karger AG, Basel \\
www.karger.com/cpb
\end{tabular}}

Hu et al.: Effects of STAT3 Targeting by Let-7a on T-Cells in Psoriasis

\section{Disclosure Statement}

The authors have declared that no competing interests exist.

\section{References}

1 Kim DS, Lee J, Kim SH, Kim SM, Lee MG: Mean platelet volume is elevated in patients with psoriasis vulgaris. Yonsei Med J 2015;56:712-718.

-2 An J, Li T, Dong Y, Li Z, Huo J: Terminalia Chebulanin Attenuates Psoriatic Skin Lesion via Regulation of Heme Oxygenase-1. Cell Physiol Biochem 2016;39:531-543.

-3 Oliveira Mde F, Rocha Bde O, Duarte GV: Psoriasis: classical and emerging comorbidities. An Bras Dermatol 2015;90:9-20.

4 Gupta R, Debbaneh MG, Liao W: Genetic Epidemiology of Psoriasis. Curr Dermatol Rep 2014;3:61-78.

5 Thom N, Ritchlin CT, Zhang X, Reveille J, Weisman MH: Prevalence of chronic axial pain, inflammatory back pain, and spondyloarthritis in diagnosed psoriasis. Arthritis Care Res (Hoboken) 2015;67:829-835.

6 Demir HD, Kalkan G, Kurt S, Gunes A, Sezer E, Erkorkmaz U: Relationship between retinal sensitivity and disease activity in patients with psoriasis vulgaris. Clinics (Sao Paulo) 2015;70:14-17.

7 Zhou J, Gao Y, Yi X, Ding Y: Ginsenoside Rh2 Suppresses Neovascularization in Xenograft Psoriasis Model. Cell Physiol Biochem 2015;36:980-987.

-8 Zhang Y, Tu C, Zhang D, Zheng Y, Peng Z, Feng Y, Xiao S, Li Z: Wnt/beta-Catenin and Wnt5a/Ca Pathways Regulate Proliferation and Apoptosis of Keratinocytes in Psoriasis Lesions. Cell Physiol Biochem 2015;36:1890-1902.

>9 Xiong H, Xu Y, Tan G, Han Y, Tang Z, Xu W, Zeng F, Guo Q: Glycyrrhizin ameliorates imiquimod-induced psoriasis-like skin lesions in BALB/c mice and inhibits TNF-alpha-induced ICAM-1 expression via NFkappaB/MAPK in HaCaT cells. Cell Physiol Biochem 2015;35:1335-1346.

10 Kofoed K, Skov L, Zachariae C: New drugs and treatment targets in psoriasis. Acta Derm Venereol 2015;95:133-139.

11 Cai Y, Fleming C, Yan J: New insights of T cells in the pathogenesis of psoriasis. Cell Mol Immunol 2012;9:302-309.

12 Martin G, Guerard S, Fortin MM, Rusu D, Soucy J, Poubelle PE, Pouliot R: Pathological crosstalk in vitro between T lymphocytes and lesional keratinocytes in psoriasis: necessity of direct cell-to-cell contact. Lab Invest 2012;92:1058-1070.

13 Gunderson AJ, Mohammed J, Horvath FJ, Podolsky MA, Anderson CR, Glick AB: CD8(+) T cells mediate RASinduced psoriasis-like skin inflammation through IFN-gamma. J Invest Dermatol 2013;133:955-963.

14 Takeshita J, Callis Duffin K, Shin DB, Krueger GG, Robertson AD, Troxel AB, Van Voorhees AS, Gelfand JM: Patient-reported outcomes for psoriasis patients with clear versus almost clear skin in the clinical setting. J Am Acad Dermatol 2014;71:633-641.

15 Cho KJ, Song J, Oh Y, Lee JE: MicroRNA-Let-7a regulates the function of microglia in inflammation. Mol Cell Neurosci 2015;68:167-176.

-16 He FC, Meng WW, Qu YH, Zhou MX, He J, Lv P, Ming L: Expression of circulating microRNA-20a and let-7a in esophageal squamous cell carcinoma. World J Gastroenterol 2015;21:4660-4665.

17 Shishodia G, Shukla S, Srivastava Y, Masaldan S, Mehta S, Bhambhani S, Sharma S, Mehrotra R, Das BC, Bharti AC: Alterations in microRNAs miR-21 and let-7a correlate with aberrant STAT3 signaling and downstream effects during cervical carcinogenesis. Mol Cancer 2015;14:116.

18 Shishodia G, Verma G, Srivastava Y, Mehrotra R, Das BC, Bharti AC: Deregulation of microRNAs Let-7a and miR-21 mediate aberrant STAT3 signaling during human papillomavirus-induced cervical carcinogenesis: role of E6 oncoprotein. BMC Cancer 2014;14:996.

19 Grossman RM, Krueger J, Yourish D, Granelli-Piperno A, Murphy DP, May LT, Kupper TS, Sehgal PB, Gottlieb AB: Interleukin 6 is expressed in high levels in psoriatic skin and stimulates proliferation of cultured human keratinocytes. Proc Natl Acad Sci U S A 1989;86:6367-6371.

-20 Wolk K, Haugen HS, Xu W, Witte E, Waggie K, Anderson M, Vom Baur E, Witte K, Warszawska K, Philipp S, Johnson-Leger C, Volk HD, Sterry W, Sabat R: IL-22 and IL-20 are key mediators of the epidermal alterations in psoriasis while IL-17 and IFN-gamma are not. J Mol Med (Berl) 2009;87:523-536. 


\section{Cellular Physiology Cell Physiol Biochem 2017;42:115-125 \begin{tabular}{l|l} 
DOI: 10.1159/000477120 & O 2017 The Author(s). Published by S. Karger AG, Basel \\
www.karger.com/cpb
\end{tabular}}

Hu et al.: Effects of STAT3 Targeting by Let-7a on T-Cells in Psoriasis

21 Di Cesare A, Di Meglio P, Nestle FO: The IL-23/Th17 axis in the immunopathogenesis of psoriasis. J Invest Dermatol 2009;129:1339-1350.

22 Lovendorf MB, Zibert JR, Gyldenlove M, Ropke MA, Skov L: MicroRNA-223 and miR-143 are important systemic biomarkers for disease activity in psoriasis. J Dermatol Sci 2014;75:133-139.

23 Huang RY, Li L, Wang MJ, Chen XM, Huang QC, Lu CJ: An Exploration of the Role of MicroRNAs in Psoriasis: A Systematic Review of the Literature. Medicine (Baltimore) 2015;94:e2030.

-24 Brauchli YB, Jick SS, Meier CR: Statin use and risk of first-time psoriasis diagnosis. J Am Acad Dermatol 2011;65:77-83.

25 Faria JR, Aarao AR, Jimenez LM, Silva OH, Avelleira JC: Inter-rater concordance study of the PASI (Psoriasis Area and Severity Index). An Bras Dermatol 2010;85:625-629.

-26 M PN: World Medical Association publishes the Revised Declaration of Helsinki. Natl Med J India 2014;27:56.

-27 Cao Q, Li YY, He WF, Zhang ZZ, Zhou Q, Liu X, Shen Y, Huang TT: Interplay between microRNAs and the STAT3 signaling pathway in human cancers. Physiol Genomics 2013;45:1206-1214.

28 Meng F, Henson R, Wehbe-Janek H, Smith H, Ueno Y, Patel T: The MicroRNA let-7a modulates interleukin6-dependent STAT-3 survival signaling in malignant human cholangiocytes. J Biol Chem 2007;282:82568264.

29 Jinnin M: Various applications of microRNAs in skin diseases. J Dermatol Sci 2014;74:3-8.

-30 Makino K, Jinnin M, Hirano A, Yamane K, Eto M, Kusano T, Honda N, Kajihara I, Makino T, Sakai K, Masuguchi S, Fukushima S, Ihn H: The downregulation of microRNA let-7a contributes to the excessive expression of type I collagen in systemic and localized scleroderma. J Immunol 2013;190:3905-3915.

-31 Litvinov IV, Bizet AA, Binamer Y, Jones DA, Sasseville D, Philip A: CD109 release from the cell surface in human keratinocytes regulates TGF-beta receptor expression, TGF-beta signalling and STAT3 activation: relevance to psoriasis. Exp Dermatol 2011;20:627-632.

-32 Cenit MC, Ortego-Centeno N, Raya E, Callejas JL, Garcia-Hernandez FJ, Castillo-Palma MJ, Fernandez-Sueiro JL, Magro C, Solans R, Castaneda S, Camps M, Hidalgo A, Espinosa G, Gonzalez-Gay MA, Gonzalez-Escribano MF, Martin J: Influence of the STAT3 genetic variants in the susceptibility to psoriatic arthritis and Behcet's disease. Hum Immunol 2013;74:230-233.

-33 Miyoshi K, Takaishi M, Nakajima K, Ikeda M, Kanda T, Tarutani M, Iiyama T, Asao N, DiGiovanni J, Sano S: Stat3 as a therapeutic target for the treatment of psoriasis: a clinical feasibility study with STA-21, a Stat3 inhibitor. J Invest Dermatol 2011;131:108-117.

34 Harden JL, Johnson-Huang LM, Chamian MF, Lee E, Pearce T, Leonardi CL, Haider A, Lowes MA, Krueger JG: Humanized anti-IFN-gamma (HuZAF) in the treatment of psoriasis. J Allergy Clin Immunol 2015;135:553556.

35 Gonzalez-Navajas JM, Lee J, David M, Raz E: Immunomodulatory functions of type I interferons. Nat Rev Immunol 2012;12:125-135.

-36 Hashioka S, Klegeris A, Qing H, McGeer PL: STAT3 inhibitors attenuate interferon-gamma-induced neurotoxicity and inflammatory molecule production by human astrocytes. Neurobiol Dis 2011;41:299307.

-37 Kim TG, Jee H, Fuentes-Duculan J, Wu WH, Byamba D, Kim DS, Kim DY, Lew DH, Yang WI, Krueger JG, Lee MG: Dermal clusters of mature dendritic cells and T cells are associated with the CCL20/CCR6 chemokine system in chronic psoriasis. J Invest Dermatol 2014;134:1462-1465.

-38 Cai Y, Fleming C, Yan J: Dermal gammadelta T cells--a new player in the pathogenesis of psoriasis. Int Immunopharmacol 2013;16:388-391.

-39 Adamson AS, Collins K, Laurence A, O'Shea JJ: The Current STATus of lymphocyte signaling: new roles for old players. Curr Opin Immunol 2009;21:161-166.

40 Goodman WA, Young AB, McCormick TS, Cooper KD, Levine AD: Stat3 phosphorylation mediates resistance of primary human T cells to regulatory T cell suppression. J Immunol 2011;186:3336-3345.

41 Siegel AM, Heimall J, Freeman AF, Hsu AP, Brittain E, Brenchley JM, Douek DC, Fahle GH, Cohen JI, Holland SM, Milner JD: A critical role for STAT3 transcription factor signaling in the development and maintenance of human T cell memory. Immunity 2011;35:806-818. 